\section{REOPERATIVE STERNOTOMY: MINIMIZING INJURY WITHOUT THE RISKS OF SYSTEMIC HEPARIN \\ To the Editor:}

We read with great interest the November 2010 article by Park and colleagues ${ }^{1}$ regarding the risk of injury during repeat sternotomy for heart surgery. In their experience of 231 patients, 267 injuries $(9 \%)$ occurred. The inhospital mortalities were $6.5 \%$ among those without injury and $18.5 \%$ among those with injury $(P<.001)$. When the injury was sustained during sternal division, the mortality was $25 \%$.

Cardiac reoperations are challenging, are time-consuming, and carry a high incidence of perioperative complications because of injury associated with cardiac structures (bleeding and hemodynamic instability). This study offers an important clinical message, highlighting the deleterious effects of reoperative sternotomy. Some centers are using extracorporeal circulation with heparinization $^{2}$ at the time of resternotomy, but this leads to prolonged anticoagulation, platelet dysfunction, fibrinolysis, coagulopathy, and morbidity.

$\mathrm{We}^{3}$ routinely perform resternotomy in complex cardiac surgery with the support of heparin-free cardiopulmonary bypass but with a heparinbonded circuit (Carmeda; Medtronic, Inc, Minneapolis, Minn). The femoral artery or axillary artery and femoral veins are cannulated before the sternotomy, and cardiopulmonary bypass is instituted with a "tip to tip" heparin-

\footnotetext{
The Editor welcomes submissions for possible publication in the Letters to the Editor section that consist of commentary on an article published in the Journal or other relevant issues. Authors should: - Include no more than 500 words of text, three authors, and five references. - Type with double-spacing. - See http://jtcs.ctsnetjournals.org/misc/ifora.shtml for detailed submission instructions. - Submit the letter electronically via jtcvs.editorialmanager.com. Letters commenting on an article published in the JTCVS will be considered if they are received within 6 weeks of the time the article was published. Authors of the article being commented on will be given an opportunity of offer a timely response ( 2 weeks) to the letter. Authors of letters will be notified that the letter has been received. Unpublished letters cannot be returned.
}

bonded circuit but without systemic heparinization. Systemic heparin (200-300 units $/ \mathrm{kg}$ ) is administered only after all structures have been isolated before aortic crossclamping (activated coagulation time longer than 400 seconds). Between 1996 and 2008 , a total of 336 patients underwent reoperative sternotomy with heparinbonded circuits for complex cardiac procedures (isolated reoperative coronary artery bypass grafting procedures were excluded in this study), with only 29 deaths ( $8.6 \%$ mortality). Only 5 of these 336 patients $(1.5 \%)$ sustained injury to the right ventricle, aorta, or bypass graft or had ventricular fibrillation during reentry; all were without hemodynamic deterioration and had both uneventful repair and outcome (no deaths). There were no cases of online heparin-bonded circuit thrombosis. Heparin-bonded circuits without systemic heparinization during resternotomy thus can be used safely in complex reoperative surgery. The heart is completed decompressed during the resternotomy, allowing easy dissection, decreasing the likelihood of injury to vital structures, and lessening bleeding without compromising the hemodynamics. This technique should be included in the armamentarium for complex reoperative cardiac surgery.

Arun K. Singh, MD Gary Stearns, CCP Andrew Maslow, MD William C. Feng, MD Carl Schwartz, MD Division of Thoracic and Cardiovascular Surgery Department of Anesthesiology The Warren Alpert Medical School of Brown University Rhode Island Hospital Providence, RI

\footnotetext{
References

1. Park CB, Suri RM, Burkhart HM, Greason KL, Dearani JA, Schaft HV, et al. Identifying patients at particular risk of injury during repeat sternotomy: analysis of 2555 cardiac reoperations. J Thorac Cardiovasc Surg. 2010;140:1028-35.
}

2. Luciani N, Anselmi A, De Geest R, Martinelli L, Perisano M, Possati G. Extracorporeal circulation by peripheral cannulation before redo sternotomy: indications and results. J Thorac Cardiovasc Surg. 2008; $136: 572-7$

3. Singh AK, Stearns G, Maslow A, Feng WC, Schwartz C. Redo sternotomy for cardiac reoperations using peripheral heparin-bonded cardiopulmonary bypass circuits without systemic heparinization: technique and results. J Thorac Cardiovasc Anesth. [Epub]. 2010 Aug 26.

doi:10.1016/j.jtcvs.2010.11.049

\section{Reply to the Editor:}

My coworkers and I greatly appreciate the letter by Singh and colleagues concerning our recent study focused on the risks of repeat median sternotomy. Their results are clearly outstanding, and their application of heparin-bonded circuits "tip to tip" is intriguing. Their technique appears to have had a definite impact on the risk of injury during repeat sternotomy. Although we have not used this particular technology, we have more frequently used full cardiopulmonary bypass under full heparinization before performing sternotomy in recent years. As has been argued by others, we find that this approach speeds us along and does not seem to increase bleeding. It is certainly easier on our own coronary vasculature, and we agree that surgeons should take a long, hard look at means of reducing the risk of injury. Injury is not inevitable. It can be minimized.

Thoralf M. Sundt III, MD Division of Cardiovascular Surgery Mayo Clinic and Foundation Rochester, Minn

doi:10.1016/j.jtcvs.2011.01.001

\section{EIGHT YEARS AFTER AN EARLY PRIMARY KAWASHIMA OPERATION \\ To the Editor:}

In a previous article in the Journal, published 6 years ago, ${ }^{1}$ we reported a successful fenestrated Kawashima operation with antegrade pulmonary 
flow, performed as the primary palliation, in a cyanotic 5-month-old infant with left isomerism, single ventricle, interrupted inferior vena cava, and pulmonary stenosis. After 8 years of follow-up, we want to share the longterm outcome of this patient.

There is debate as to whether primary early Kawashima operation is a valuable strategy for the palliation of very young infants with left isomerism, single ventricle, and pulmonary stenosis. ${ }^{2-4}$ Consequently this procedure is rarely performed in small infants, and follow-up results are lacking.

Hemodynamic instability as a result of a more reactive pulmonary bed in the early postoperative period is a matter of concern. This was the rationale for decompressing the pulmonary circuit by means of a limited fenestration back into the heart. ${ }^{3,4}$ The benefit of fenestration in this small infant with such nearly total cavopulmonary connection was likely to be crucial and attributable to improved cardiac output. ${ }^{4}$

These benefits, however, come at the expense of lower oxygenation in later follow-up and the need for catheter intervention to close the fenestration. At the age of 4 years, our patient had desaturation to the $70 \%$ range. The presence of pulmonary arteriovenous malformations was suspected, and an elective cardiac catheterization was carried out. There was no evidence of pulmonary arteriovenous fistulas. Negative results of bubble contrast echocardiography ${ }^{6}$ were ac- companied by a pulmonary venous saturation of $98 \%$, a normal pulmonary arterial-venous transit time, and absence of reticular spongy pattern on pulmonary angiography. A significant right to left shunt through the modified fenestration, however, was revealed. Transcatheter occlusion was successfully accomplished with an 8-mm Amplatzer (AGA Medical Corp, Plymouth, Minn) septal device. Saturation increased to $94 \%$, and the cavopulmonary pressure increased from $9 \mathrm{~mm} \mathrm{Hg}$ to $11 \mathrm{~mm} \mathrm{Hg}$.

It is noteworthy that pulmonary arterial venous malformations were not the cause of desaturation. It has been reported that these patients are at risk for the development of pulmonary arterial venous fistulas early after the Kawashima operation. ${ }^{5}$ We hypothesized that the controlled antegrade pulmonary flow could have prevented or delayed the development of such malformations. ${ }^{3}$

At 8 years of follow-up, the patient is free of symptoms, leading a normal and active life for an 8-year-old girl with an oxygen saturation in the $92 \%$ to $94 \%$ range. The good ventricular function without atrioventricular valve insufficiency observed at the last follow-up could be attributable to the fact that the single ventricle was never exposed at a volume overload.

This encouraging long-term result influenced us to consider the early primary Kawashima procedure, instead of a systemic pulmonary shunt, as valuable therapeutic option for the first-stage palliation of this uncommon cardiac anomaly. Since then, 2 other cyanotic infants with the same cardiac malformation have undergone successful early fenestrated Kawashima operations.

Dante Picarelli, $M D$

Christian Kreutzer, MD

Serrana Antunez, MD

Departamento de Cardiopatias Congénitas

Centro Cardiológico Americano Sanatorio Americano Montevideo, Uruguay

\section{References}

1. Picarelli D, Montenegro JL, Antunez S, Perez W, Borbonet D. Modified fenestration technique for the Kawashima operation in a young infant. $J$ Thorac Cardiovasc Surg. 2005;129:451-2.

2. Nath DS, Carden AJ, Nussbaum DP, Shin AJ, Khemani RG, Starnes VA, et al. Can the Kawashima procedure be performed in younger patients? Ann Thorac Surg. 2009;88:581-7.

3. Hannan RL, Rossi AF, Nykanen DG, Lopez L, Alonso F, White JA, et al. The fenestrated Kawashima operation for single ventricle with interrupted inferior vena cava. Ann Thorac Surg. 2003;75: 271-3.

4. Turkoz R, Omay O, Ayabakan C, Vuran C, Tokel K, Günay I, et al. Fenestration between the left atrial appendage and left superior vena cava in Kawashima operation. Ann Thorac Surg. 2008;86: 2000-1.

5. Brown JW, Ruzmetov M, Vijay P, Rodefeld MD, Turrentine MW. Pulmonary arteriovenous malformations in children after the Kawashima operation. Ann Thorac Surg. 2005;80:1592-6.

6. Larsson ES, Solymar L, Eriksson BO, De Wahl Granelli A, Mellander M. Bubble contrast echocardiography in detecting pulmonary arteriovenous malformations after modified Fontan operations. Cardiol Young. 2001;11:505-11.

doi:10.1016/j.jtcvs.2011.01.004

\section{Notice of Correction}

Re: Westaby S, Archer N, Myerson SG. Long-term cardiac remodeling after salvage partial left ventriculectomy in an infant with anomalous left coronary artery from the pulmonary artery. J Thoracic Cardiovasc Surg. 2009;137:757-9.

In the above-noted article, funding acknowledgment was not included. The proper acknowledgment is printed below.

Dr Myerson would like to acknowledge support from the Oxford NIHR Biomedical Research Centre program. 